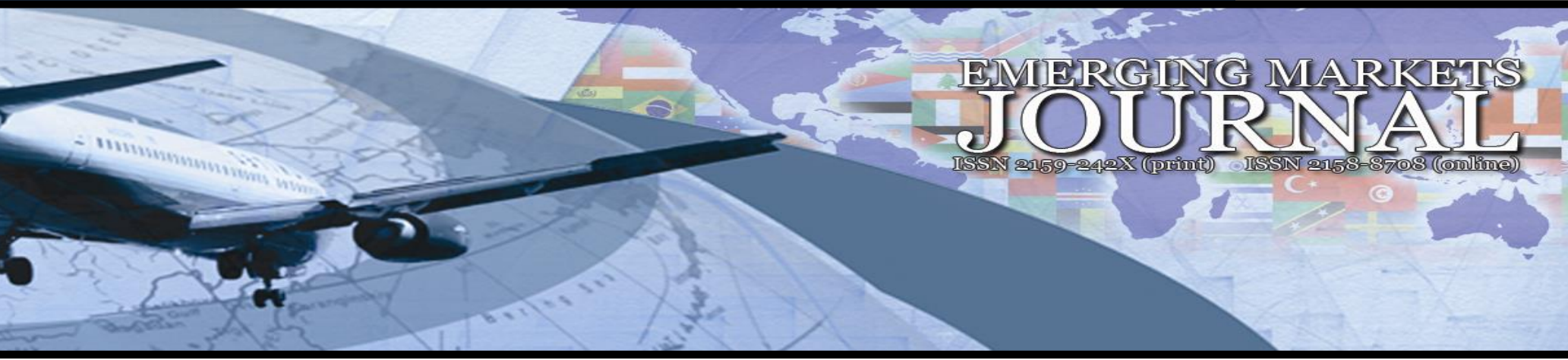

\title{
Creating Brand Image Profile by Social Media Analysis
}

\section{İbrahim Sabuncu}

Yalova University, Turkey | e-mail: isabuncu@yalova.edu.tr

\section{Berivan Edeș}

Yalova University, Turkey | e-mail: berivanedes@outlook.com

\section{Doruk Sitkıbütün}

Yalova University, Turkey | e-mail: doruk-stkbtn@yandex.com

\section{İlayda Girgin}

Yalova University, Turkey | e-mail: ilayda girgin@ hotmail.com

\section{Kadir Zehir}

Yalova University, Turkey | e-mail: kadirzehir@ outlook.com

Volume 11 No 2 (2021) ｜ＩSSN 2158-8708 (online) ｜ DOI 10.5195/emaj.2021.228 | http://emaj.pitt.edu

\begin{abstract}
The purpose of creating a brand image profile is to measure the brand perception of consumers considering brand attributes. Thus, marketing decisions can be made based on the brand's strengths and weaknesses by determining them. The brand image profile is traditionally created using the attitude scales and surveys. However, alternative methods are needed since the questionnaires' responses are careless, the number of participants is relatively low and the cost per participant is high. In this study, as an alternative method, creating a brand image profile by analyzing social media data with artificial intelligence was made for the iPhone product. Firstly, the focus group study determined the attributes related to the last version of the iPhone. Then, between December 17th, 2019 and March 23rd, 2020, 87.227 tweets that include these attributes in English were collected from the Twitter social media platform through the RapidMiner data mining tool. Sentiment analysis was performed on collected tweets by the MeaningCloud text mining tool. In this analysis, positive and negative emotions were tried to be detected through artificial intelligence algorithms. Net Brand Reputation Score (NBR) was calculated using the positive and negative tweets amount for each attribute separately. Brand image profile was created by skew analysis using NBR values. As a result, it is thought that social media analysis can be a complementary method that can be used with traditional methods in creating a brand image profile. So, it is seen as an inevitable method to use in further studies to make sentiment analysis by processing raw data received from the Social Media platforms through artificial intelligence algorithms to transform the product label or the perspectives of an event into meaningful information.
\end{abstract}

Keywords: Social Media Analysis, Brand Image Profile, Text Mining, Net Brand Reputation, Twitter

\section{(cc) EY}

New articles in this journal are licensed under a Creative Commons Attribution 3.0 United States License.

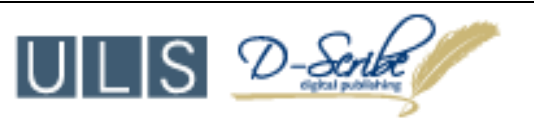

This journal is published by the University Library System of the University of Pittsburgh as part of its D-Scribe Digital Publishing Program, and is cosponsored by the University of Pittsburgh Press. 


\section{Creating Brand Image Profile by Social Media Analysis}

\author{
İbrahim Sabuncu \\ Berivan Edeş \\ Doruk Sitkıbütün \\ İlayda Girgin \\ Kadir Zehir
}

\section{Introduction}

Product or service provides several benefits to the consumers. These benefits are functionality, rationality, sensuality, individualism, and brandconsumer relations. A brand profile is relating to how the brand is perceived on these benefits (Charan, 2015a). A brand is one of the most critical factors that enable the product to be distinguished and preferred by a consumer. A brand is image, confidence, quality, good service, satisfaction and self-expression from a consumers' perspective. The consumers faced with selecting an extensive range of products are selective in the intensive consumption society. Branded products with a strong image profile are preferred at this point (Lee and Bradlow, 2011). Due to the lack of studies conducted with the social media analysis in the literature, we believe that the mentioned gap in the literature is filled with this research.

The research's primary purpose is to provide some practical information for Apple producers about the attributes needed in terms of consumers' points of view to manage the budget of each attribute. Besides, a contribution is made to increase the satisfaction level of iPhone-addicted users. Indirectly, competition in the market will be increased, and economic mobility will be stimulated.

Brand image is the consumers' perception of a brand. Brand image tracking identifies these perceptions based on its strengths and weaknesses to improve marketing strategies (Charan, 2015a). The purpose of brand image tracking is to measure consumers' brand perception via its relationship with the relevant attributes. Thus, the brand's strengths and weaknesses are obtained and categorized according to the properties like age, gender and demographic attributes.

Traditional methods such as surveys and focus group studies can be utilized for brand image tracking. Traditional methods are based on a series of predefined product features or interpretations of dimensions derived from consumer surveys (Lee and Bradlow, 2011). These methods provide some practical input for the studies. However, they are costly and if they are not answered correctly, the study may give incorrect results unless it is not under control.
As an alternative to traditional methods, social media analysis can be implemented for consumer satisfaction by taking raw data as input from them, carrying out a transaction and making a meaningful inference. Thanks to digitalization and the widespread usage of social media, most of the internet's content has been produced by social media users. Therefore, the amount and importance of this content increase with high acceleration. Analyses of data obtained from social media are based on individuals' thoughts. Therefore, the risk of getting wrong results can be eliminated. In addition to that, the analysis performed using data obtained are more cost-effective than other methods.

In this study, iPhone's brand image profile was created using data obtained from Twitter, a commonly used social media platform. The focus group discussion determined the required attributes for creating a brand image profile. The total number of 87.227 tweets containing the iPhone attributes was obtained from Twitter using RapidMiner Studio data mining software between December 17th, 2019 and March 23rd, 2020.

All Tweets obtained have been analyzed and interpreted to generate an image profile for the iPhone product. An image profile survey, one of the traditional methods, was implemented for iPhone as an additional study. In order to evaluate the image profile study results, the results of both studies were compared.

\section{Literature Review}

Determining the brand's image and attribute by using data obtained from social media is not a common practice. Therefore, few studies in this field could be found in the literature. One of the first studies in this regard is made by Lee and Bradlow (2011). They presented a method to determine product attributes and the brand's position on the comments automatically extracted from online customer reviews. These comments were obtained from websites as well as social media platforms with the help of general-purpose software. Then, they tested their methods by analyzing six-year customer review data on digital cameras. In their study, three brands of digital cameras (Olympus, Hewlett-Packard (H.P.) and Fuji) were compared by using the clustering technique based on the words "Zoom," "Battery Life," "Image Quality" and "Memory". Thus, they conducted market research by using both text mining and K-means methods. Lee and Bradlow (2011) demonstrated that social media could be used for marketing research, but their methods cannot be compared with the traditional ones.

Culotta and Cutler (2016) compared traditional brand image methods with the social media analytics approach. In this study, consumer perception was an essential component of brand value and marketing strategy. They considered that traditional approaches such as surveys to monitor such perceptions are costly, time-consuming and inaccurate. Therefore, they proposed analyzing the social connections of the brand on Twitter to measure the brand's perception according to the attributes. Through this method, they rated three 
perceptual attributes for more than 200 brands. Also, they collected data by direct survey method. Finally, they had compared the results of both studies and found a consistently strong correlation in the results. Various companies from the automotive, textile, food and cosmetics industries have been chosen to make comparisons. For example, when they chose a brand from the automotive industry, they were compared in terms of economic and luxury criteria. At the same time, they received a product selected from the cosmetic sector only as economically evaluable. So, considering a brand (e.g., smart automobile) and an attribute (e.g., being environmentally friendly), they aimed to develop an automated method to assign a brand score. They made the "environment", "luxury" and "nutritious" queries to collect samples for each of the three perceptual attributes using the "Twitter List search method. Up to 50.000 IDs of Twitter followers were collected for each of the exemplary brand accounts. With this approach, they provided a reliable, flexible and scalable method to track brand perceptions and provide a basis for future work to understand brand-consumer social media relationships.

Another study that criticizes traditional methods and expresses social media as an alternative belongs to Pournarakis and his friends (2017). They claimed that traditional data collection and analysis methods (e.g. surveys and telephone or face-to-face interviews) are not enough in evaluating brand performance. They presented a computational model combining subject and sentiment classification to uncover useful topics from consumers' percentage on social media. To show the model's validity, they collected data about Uber's transport network via Twitter for four months. Over 280.000 tweets were collected by the Streaming API' Tool of Twitter and analyzed. During the data collection process, the focus was on collecting tweets that clearly express "Uber" using "Mention" and "Hash-tag". They stated that their results reveal consumer perception and produce brand awareness as well as brand meaning, the two fundamental brand value dimensions.

The surveyed studies show that, customers' brand perception and the brand's successful performance can be measured with social media data. However, is it possible to use social media analysis to obtain the brand's characteristics that affect the customer, create a brand image profile according to these attributes and develop marketing strategies based on this information? To search for the answer to this question, a case study was done for iPhone using the method described below.

\section{Data and Methodology}

To create a brand image profile by social media analysis, the steps described below have been applied. The analysis process is summarized in Figure 1.

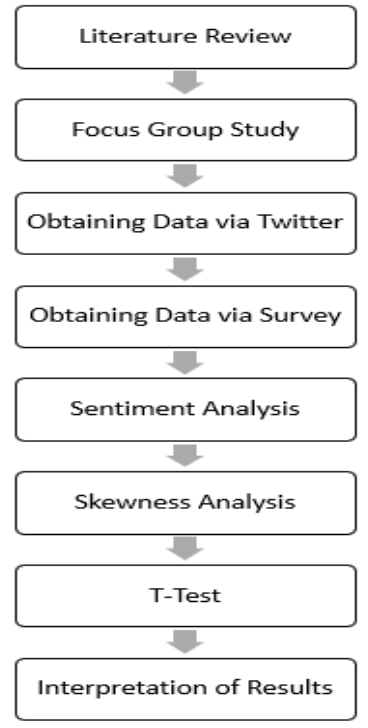

\section{Figure 1. Process Flow}

Source: Authors' own compilation

The social media analysis method suggested to create a brand image profile consists of 7 steps that are described below:

1. In the beginning, by focus group work, the factors/attributes that affect the brand preference in the relevant industry should be determined.

2. Social media posts that consist of the company's brand name and the attributes determined in step 1 had been collected separately. This can also be done through different social media channels such as Twitter and Facebook.

3. Sentiment analysis of data collected from social media had been performed. This can be done by using some programs such as Phyton, $\mathrm{R}$ and RapidMiner. Afterwards, "total", "positive", "negative" and "neutral" mentioned numbers had been determined for each attribute. There are some modules such as MeaningCloud and Aylien that can be used for this process.

4. Net Brand Reputation (NBR) is a new method to measure brand reputation (Vidya, Fanany and Budi, 2015). Considering the NBR's strong and weak attributes, the brand had been determined. The brand image profile had been created by skew analysis by taking the difference of all these qualities from the average value.

5. In addition to this, using the survey method, a complementary study had been conducted to compare the results obtained through social media analysis.

6. To measure the significance of the average difference between the survey study results and the results of the social media analysis, the T-Test had been applied using statistical software "Jamovi" tool2.

7. Finally, the brand image profile had been created for decision-making about the marketing mix. According to the created brand image profile, strong attributes that should be emphasized in advertisements had been identified. Besides, the attributes that need improvement 
and focus on innovation studies can be determined for further studies.

The process followed in this section is based on similar studies in the field. Literature research was the biggest motivation to be able to follow the study flow process. The traditional methods that constitute this research's inputs are essential starting points in feeding the subsequent processes in the research.

The proposed social media analysis model had been implemented for iPhone. The steps of implementation are described below.

The first step of the study to create a brand image profile for the Apple brand's iPhone product is to determine keywords about related attributes. One of the traditional methods, which is the focus group discussion method, was used. The focus group study was run on December 11th, 2019, by gathering international students from 6 different nationalities. To ensure the homogeneity of the sample of 6 people, attention was paid to the fact that the participants were from nationalities with different cultures and norms. The demographic characteristics of each participant were determined by asking them questions. Participants were asked preprepared questions about iPhone. The prepared questions are provided in the Appendix section. Thanks to this approach, the keywords to be used in the study were determined. These six keywords that are important for brand preferences determined in the focus group discussion are "iPhone's price", "iPhone's camera", "iPhone's memory", "iPhone's security", "iPhone's speed performance" and "iPhone's design" The results of the focus group study is summarized in Table 1 .
Table 1: Results of the Focus Group Study

\begin{tabular}{|c|c|c|c|c|c|c|c|}
\hline Keyword & I. & II. & $\begin{array}{c}\text { III } \\
\text { • }\end{array}$ & IV. & V. & VI. & Total \\
\hline Quality & $\checkmark$ & $\begin{array}{l}\checkmark \\
\checkmark\end{array}$ & & $\checkmark$ & $\checkmark$ & & 5 \\
\hline Price & & $\begin{array}{l}\checkmark \\
\checkmark\end{array}$ & $\begin{array}{l}\checkmark \\
\checkmark \\
\checkmark \\
\checkmark\end{array}$ & $\begin{array}{l}\checkmark \\
\checkmark \\
\checkmark \\
\checkmark\end{array}$ & $\begin{array}{l}\sqrt{ } \\
\checkmark\end{array}$ & $\checkmark$ & 13 \\
\hline Speed & $\checkmark$ & $\begin{array}{l}\checkmark \\
\checkmark\end{array}$ & $\checkmark$ & $\begin{array}{l}\checkmark \\
\checkmark\end{array}$ & $\begin{array}{l}\checkmark \\
\checkmark\end{array}$ & $\checkmark$ & 9 \\
\hline Security & $\checkmark$ & $\checkmark$ & $\begin{array}{l}\checkmark \\
\checkmark\end{array}$ & $\checkmark$ & $\checkmark$ & $\begin{array}{l}\checkmark \\
\checkmark \\
\checkmark \\
\checkmark\end{array}$ & 10 \\
\hline Functionality & & $\checkmark$ & & & $\checkmark$ & & 2 \\
\hline Luxury & & $\begin{array}{l}\checkmark \\
\checkmark\end{array}$ & & $\checkmark$ & & & 3 \\
\hline Popularity & $\sqrt{ }$ & & & & & & 1 \\
\hline Camera & $\begin{array}{l}\checkmark \\
\checkmark \\
\checkmark\end{array}$ & $\checkmark$ & $\begin{array}{l}\checkmark \\
\checkmark \\
\checkmark\end{array}$ & $\checkmark$ & $\begin{array}{l}\checkmark \\
\checkmark \\
\checkmark\end{array}$ & $\checkmark$ & 12 \\
\hline Marketing & & & & $\begin{array}{l}\checkmark \\
\checkmark \\
\checkmark \\
\checkmark\end{array}$ & & $\begin{array}{l}\checkmark \\
\checkmark\end{array}$ & 6 \\
\hline Memory & $\begin{array}{l}\checkmark \\
\checkmark\end{array}$ & $\begin{array}{l}\checkmark \\
\checkmark\end{array}$ & $\checkmark$ & $\checkmark$ & $\begin{array}{l}\checkmark \\
\checkmark\end{array}$ & $\checkmark$ & 9 \\
\hline $\begin{array}{c}\text { Relationship } \\
\text { with Other } \\
\text { Devices }\end{array}$ & & & $\checkmark$ & & & & 1 \\
\hline Design & $\checkmark$ & $\begin{array}{l}\checkmark \\
\checkmark\end{array}$ & $\begin{array}{l}\checkmark \\
\checkmark\end{array}$ & $\begin{array}{l}\checkmark \\
\checkmark\end{array}$ & $\checkmark$ & $\begin{array}{l}\checkmark \\
\checkmark\end{array}$ & 10 \\
\hline Ownership & & & & $\checkmark$ & $\checkmark$ & $\checkmark$ & 3 \\
\hline
\end{tabular}

Source: Authors' own compilation

By exploiting the keywords in the previous step, 87.227 tweets were obtained between December 17th, 2019 and March 23rd, 2020, using the "Rapidminer Studio" tool on the Twitter platform. The model created on RapidMiner to collect Twitter data and analyze the sensitivity is provided in Figure 2. 


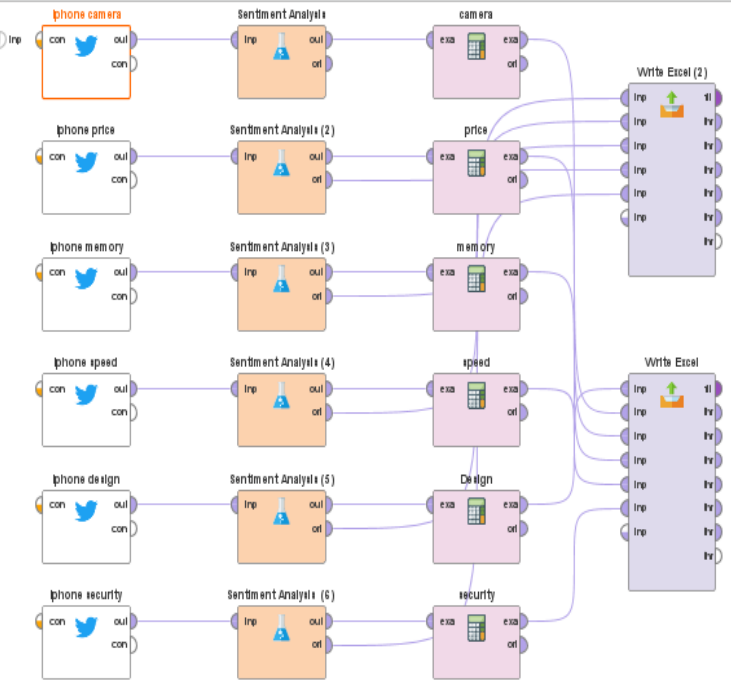

Figure 2. Data Retrieval Operation Model with RapidMiner

Source: Authors' own compilation

The "Search Twitter" modules were used for data retrieval operations from Twitter. A separate "Search Twitter" module had been created for each keyword. The parameters of this module are set as follows:

- Connection Entry: This section is used to establish a bridge with a Twitter account, which has already been installed through the link section.

- Query: This is the part where the keywords are written and entered. Six keywords determined by the focus group study were written separately for six modules.

- Result Type: This parameter specifies the preferred search result type. For recent tweeting, 'recent or popular' has been selected as 'recent' for all subsequent actions.

- Language: This parameter limits the retrieved tweets to the language specified by the ISO 639-1 code. The language of the text to be used for sentiment analysis must be unique. That is why English was chosen as the most widely used language. The command "en" was entered as the international abbreviation of English Language in the relevant section.

Sentiment analysis had been performed to make the tweet data meaningful. Sentiment analysis is a technique used to reveal personal perceptions from raw data available on the internet. It is used for classifying users' opinions and thoughts from social media as positive, negative and neutral emotions (Bhardwaj et al., 2015).

MeaningCloud "Sentiment Analysis" module had been added as RapidMiner extension and used to perform sensitivity analysis in the model. MeaningCloud visually depicts the result of polarity and sensitivity analysis for discussion (Aswani et al., 2018). The tweets that this module had categorized are as negative/ positive/ neutral/ negative+/ and positive+
After the Sentiment Analysis, the collected comments had been evaluated. The values and thoughts that users pay attention to when buying an iPhone had been categorized. Before the sentiment analysis be carried out, 1.000 comments had been read one by one to measure the created sentiment analysis algorithm's accuracy. They were categorized as positive, negative, neutral, negative+ and positive+ by non-algorithmic processes. The actual values of these interpretations had been compared with the test results. As shown in Table 1, the error rate of NBR scores is only 7,29\%, although the error rate in emotion polarities is high.

Table 2: Manually Sentiment Analysis and Sentiment Analysis through RapidMiner

\begin{tabular}{|l|r|r|}
\hline $\begin{array}{c}\text { POLARITY } \\
\text { (TEXT) }\end{array}$ & $\begin{array}{c}\text { COUNT } \\
\text { (POLARITY(TEXT) } \\
\text { Manually Sentiment } \\
\text { Analysis }\end{array}$ & $\begin{array}{c}\text { COUNT } \\
\text { (POLARITY(TEXT)) } \\
\text { Sentiment Analysis } \\
\text { Through RapidMiner }\end{array}$ \\
\hline N & 50 & 89 \\
\hline N+ & 43 & 14 \\
\hline NEU & 120 & 41 \\
\hline NONE & 217 & 507 \\
\hline P & 339 & 303 \\
\hline P+ & 231 & 46 \\
\hline SUM & 1.000 & 1.000 \\
\hline NBR & 3,84 & 3,56 \\
\hline
\end{tabular}

Source: Authors' own compilation

NBR is a brand's reputation value digitally, meaningfully close to the Net Promoter Score (Armstrong, Kotler and Opresnik, 2016). In this study, positive and negative thoughts were used as data by considering Net Brand Reputation when creating the iPhone's brand profile. This study aims to analyze the emotions and perform a sentiment analysis of the individuals by taking advantage of social media. Thanks to exploiting this, the opinions of individuals about the product were determined. These detected data had been analyzed through the "MeaningCloud" tool.

NBR Formula: (Vidya, Fanany and Budi, 2015)

$\left(\frac{\text { Positive Mentions-Negative Mentions }}{\text { Positive Mentions }+ \text { Negative Mentions }}\right) * 100 \%$

A survey was conducted to compare the results of social media analysis and to determine the NBR values of the keywords. Participants were asked to answer the following questions.

- Can you rate the camera feature of the iPhone between 1-5?

- Can you rate the design feature of the iPhone between 1-5?

- Can you rate the price feature of the iPhone between 1-5?

- Can you rate the performance (speed) feature of the iPhone between 1-5?

- Can you rate the memory feature of the iPhone between 1-5? 
- Can you rate the security feature of the iPhone between $1-5$ ?

Survey questions were prepared in parallel with the focus group study. The attributes included in the questions were the same as the keywords obtained from the focus group discussion. The answers given to the questions had been collected with the Likert scale's help in the range of 1-5. For the research, 342 individuals were reached using the questionnaire link created by the 'SurveyMonkey' application.

\section{Results}

The distribution of the tweets retrieved from social media analysis according to the keywords and emotions they contain is provided in Table 3 . Information in Table 3 is more understandable after visualizing it with Figure 3 and the radar chart in Figure 4.

Table 3: Result of Social Media Analysis

\begin{tabular}{|c|c|c|c|c|c|c|c|}
\hline & $\mathbf{N}$ & $\mathrm{N}+$ & NEU & $\mathbf{P}$ & $\mathbf{P}+$ & SUM & NBR \\
\hline 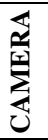 & 3.071 & 592 & 1.703 & 9.821 & 2.891 & 23.361 & 3,63 \\
\hline 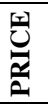 & 3.449 & 848 & 1.186 & 15.684 & 2.013 & 29.746 & 3,63 \\
\hline 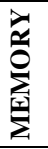 & 469 & 94 & 615 & 3.799 & 185 & 6.248 & 3,68 \\
\hline 言 & 414 & 65 & 241 & 2.753 & 192 & 4.886 & 3,71 \\
\hline $\begin{array}{l}Z \\
\mathbf{Z} \\
\overline{\mathscr{O}} \\
\text { 至 }\end{array}$ & 317 & 190 & 277 & 9.126 & 1.199 & 11.755 & 3,97 \\
\hline 岂 & 2.521 & 814 & 576 & 3.947 & 369 & 11.231 & 3,07 \\
\hline$\sum_{\infty}$ & 10.241 & 2.603 & 4.598 & 45.130 & 6.849 & 87.227 & \\
\hline
\end{tabular}

Source: Authors' own compilation

According to the graphic prepared to exploit the data visualization technique, those with the highest iPhone attributes scores are design, memory and performance (speed). The 'Design' attribute has the highest NBR score. However, the commonly spoken attribute is 'Price.' This result is consistent with the study conducted by Amron (2018) using the survey method for iPhone. In that study (Amron, 2018), it is stated that the price is the most critical feature.

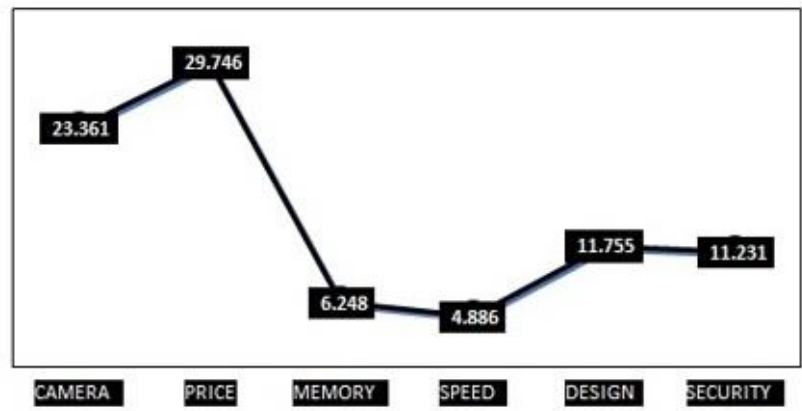

Figure 3. Sum of Tweets

Source: Authors' own compilation

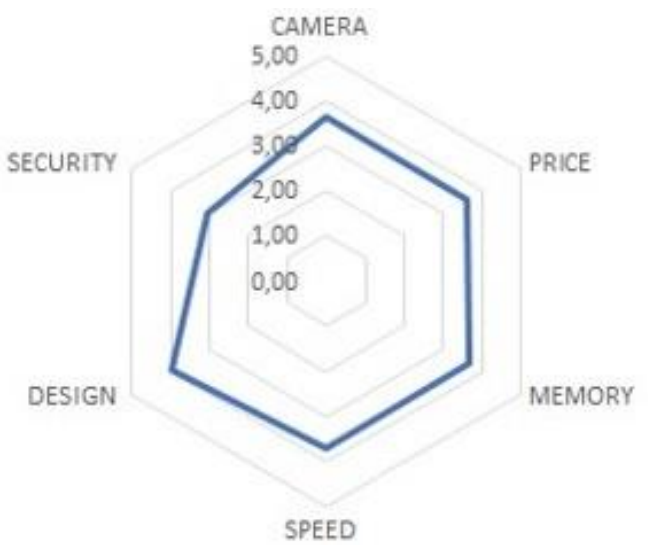

Figure 4. Social Media Analysis NBR Scores Radar Chart

Source: Authors' own compilation

The results of the two methods were compared. According to social media analysis, the highest score attributes are "design, speed and memory", while the lowest score attributes are "security". In general, the most mentioned attribute is "Price". According to the survey method, the highest-scoring attribute was determined as "camera", "design" and "security", while the lowestscoring attribute was "Price".

Table 4: Results of Creating a Brand Image Profile with Social Media Analysis and Survey Method for iPhone

\begin{tabular}{|c|c|c|}
\hline & $\begin{array}{c}\text { Social Media } \\
\text { Analysis NBR }\end{array}$ & $\begin{array}{c}\text { Survey } \\
\text { Method NBR }\end{array}$ \\
\hline Camera & 3,63 & 4,24 \\
\hline Price & 3,63 & 2,39 \\
\hline Memory & 3,68 & 3,36 \\
\hline Speed & 3,71 & 4,03 \\
\hline Design & 3,97 & 4,12 \\
\hline Security & 3,07 & 4,12 \\
\hline AVG. & 3,61 & 3,71 \\
\hline
\end{tabular}

Source: Authors' own compilation 
The attributes are demonstrated more visually with the Survey Method NBR Scores Radar Chart in Figure 5.

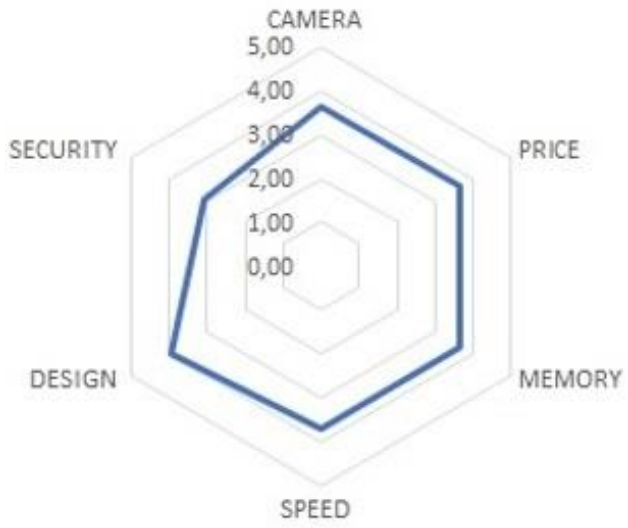

Figure 5. Survey Method NBR Scores Radar Chart

Source: Authors' own compilation

The data obtained throughout the study created an NBR score of 6 qualities in two different categories. These scores had been evaluated as separated observations and compared with the Independent T-Test. According to the T-Test result, the p-value was determined as 0,777 and this result proves that there is no statistical difference between both studies.

To measure whether there is a statistical difference between the 6 NBR scores obtained from the two evaluation results, the Independent Samples T-Test had been carried out with the "Jamovi" tool at 0,05 significance level.

Table 5: Comparison of Social Media Analysis and Survey Method Results

\begin{tabular}{|c|c|c|c|c|c|c|c|c|c|c|}
\hline & $\mathbf{N}$ & $\mathrm{N}+$ & NEU & $\mathbf{P}$ & P+ & SUM & $\begin{array}{l}\text { Survey } \\
\text { Method } \\
\text { NBR }\end{array}$ & $\begin{array}{c}\text { Social } \\
\text { Media } \\
\text { NBR }\end{array}$ & $\begin{array}{c}\text { Error } \\
\text { Rate }\end{array}$ & $\begin{array}{c}\text { Result } \\
\text { of } \\
\text { T-Test }\end{array}$ \\
\hline 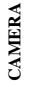 & 7 & 17 & 38 & 92 & 183 & 337 & 4,24 & 3,63 & $\% 16,80$ & $<0,001$ \\
\hline 悉 & 70 & 130 & 62 & 31 & 46 & 339 & 2,39 & 3,63 & $\% 34,15$ & $<0,001$ \\
\hline $\begin{array}{l}\stackrel{0}{0} \\
\text { in }\end{array}$ & 42 & 60 & 60 & 73 & 106 & 341 & 3,36 & 3,68 & $\% 8,69$ & $<0,001$ \\
\hline $\begin{array}{l}\text { त्र्त } \\
\text { क्ष }\end{array}$ & 18 & 17 & 63 & 83 & 160 & 341 & 4,03 & 3,71 & $\% 8,62$ & $<0,001$ \\
\hline 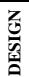 & 13 & 19 & 46 & 93 & 171 & 342 & 4,12 & 3,97 & $\% 3,77$ & $<0,001$ \\
\hline 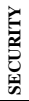 & 16 & 29 & 37 & 62 & 196 & 340 & 4,12 & 3,07 & $\% 34,20$ & $<0,001$ \\
\hline 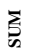 & 166 & 272 & 306 & 434 & 862 & 2.040 & & & & \\
\hline
\end{tabular}

Source: Authors' own compilation

The collected tweets and responses to the questionnaires had been classified between 1 and 5, and each was accepted as individual observation values. The $\mathrm{p}$-value obtained from independent observation of the TTest based on qualifications was accepted as less than
0,01 . This means that, the results obtained by both methods were different from each other. However, when all the answers were accepted under a single title and considered as evaluations of the iPhone product, the TTest result is 0,096 . This value shows that, two different methods do not differ from each other at $95 \%$ confidence level.

The average of scores assigned to the attributes had been calculated to generate the brand image profile. Each attribute score was subtracted from this average value to generate an image profile of the brand and make the data visualizable. Making data visualizable allows seeing clearly which qualities are below the average value and which are above (Charan, 2015b).

The results of social media analysis and survey application for the research are shown below.

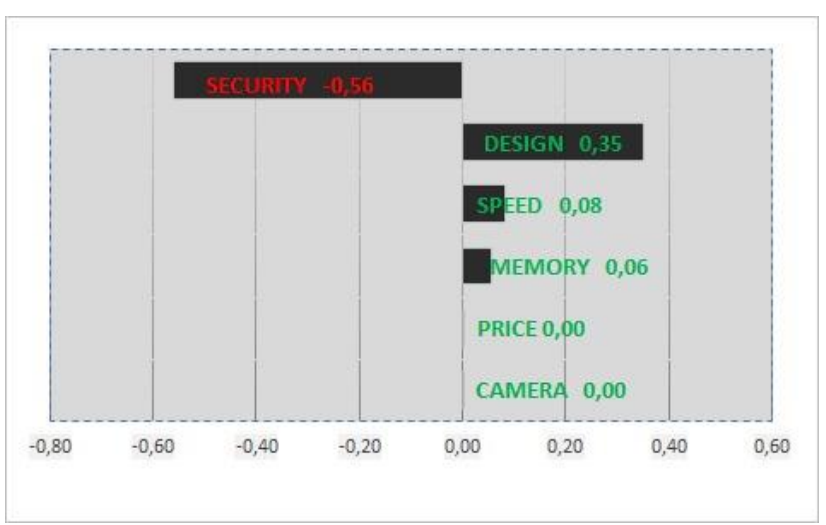

Figure 6. Skew Analysis for Social Media

Source: Authors' own compilation

According to Twitter users $\quad(87.227$ individuals), the design can be said to be the most successful one among iPhone attributes, especially in terms of speed and memory. The word "Security" is the quality with the lowest score in the research. This is possible to use the word "Security" instead of the word "Privacy" in the study as in English. Obtained average results in the words "Price" and "Camera" show that, these qualities for iPhone do not meet the expectation but raise the brand.

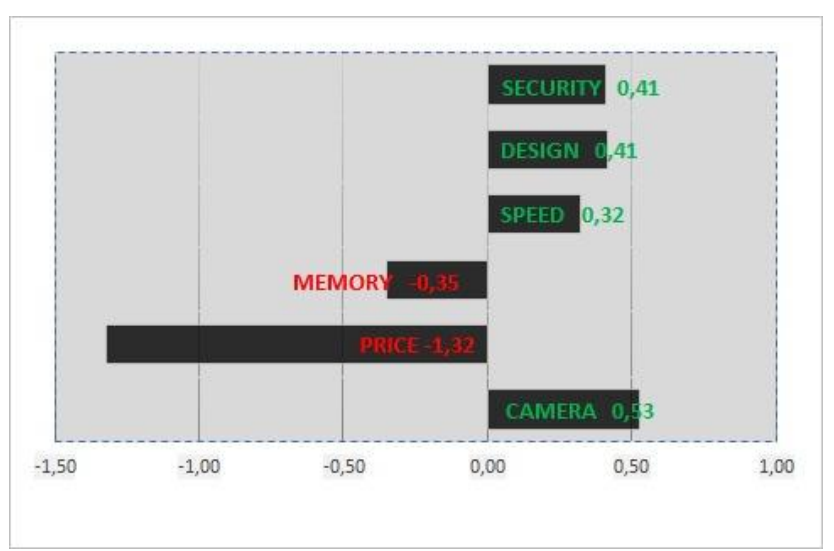

Figure 7. Skew Analysis for Survey Method

Source: Authors' own compilation 
Based on the results of survey study run on 342 individuals living in Turkey, the qualities that are most successful iPhone are observed as "Camera", "Security", "Design" and "Speed". The "Price" attribute was determined as the one with the worst score in terms of the group.

Unlike social media analysis, the survey was conducted in Turkish and the targeted demographic diversity could not be achieved as expected. The reason why the results were different from the results of the social media analysis originates from the selected sample. Thanks to the social media analysis, 87.227 people's personal opinions had been reached, while in the survey method, inconsistent answers or unanswered ones were encountered. The study samples have different demographic structures that are the structures of easy sampling. The survey was conducted different from the social media analysis. As a result, it has been revealed that the survey study, which is one of the traditional methods, did not meet the expectations expected for the targeted study. However, it has been determined that the expected value not met would be neglected at a certain level through the T-Test. On the other hand, a certain amount of time and budget is reserved for the survey. This can be seen as a negative aspect of social media analysis.

If the iPhone's strategy is compatible with its advertisements, the iPhone's brand image profile displays accuracy. Therefore, the proposed model, namely social media analysis and creation of brand image profile model, worked adequately. It responds faster than traditional methods and more participants are reached. Social media analytics, one of the contributions of technology, is a very low-cost method owing to the attainableness of a high-volume population and quick response features. Also, it provides a digital platform where its users will report their level of satisfaction.

The compatibility between the results obtained from the social media analysis and the survey study was examined through the T-Test. It was revealed how meaningful the perceptions of the selected masses towards the qualities of the iPhone. A general brand pattern was developed by revealing a general image for iPhone by looking at all these attributes. It was determined what qualities of the iPhone are dominant and the extent to which they deviate from their average value.

The sub-sets were used to create a general brand profile with the help of using NBR (Net Brand Reputation) values. Thanks to the NBR values obtained from both the social media and the survey, the iPhone's status in the customer's mind has become evident.

\section{Discussion and Conclusion}

This study shows that, social media analysis is a useful method for brand image profiling. Accordingly, the social media analysis study conducted is a practical and useful model. It also allows reaching more participants faster and is less costly than traditional methods.
Based on the social media analysis conducted for the study and the results of the following survey, camera, speed and especially design characteristics are the attributes that can be brought to the fore in the market which should be given the most attention. In order to impress their users by advertising activities, marketing people should consider these three attributes. "Price", "Security", and "Memory" are the attributes that need to be compared and improved with the current level of importance in the market. The iPhone needs to find out how to proceed against these attributes. It is necessary to be concentrate on "Price", "Security" and "Memory" qualities, both in Research\&Development (R\&D) investments and in marketing activities, to be able to strengthen iPhone's position in the market. The most prominent qualities in iPhone ads are camera, design and speed. If the figures and tables of the study are examined, qualities determined according to the social media analysis are 'design and speed', and the value with the highest NBR score in the additional survey study is 'camera', which reveals the accuracy of the study.

In the light of research, some specific gaps in the literature were filled. The contribution to literature by revealing the effects of necessary inferences from social media on brands with various analysis is observed in the study. The most crucial factor to consider in terms of contribution for further studies is that, the sample volume to be selected for the study should be appropriate. Besides, attention should be paid to bringing forth the level of adaptation of more than one problem for the same purpose. The parameters that will be provided as input to the study are the essential elements in determining the study's output. Therefore, determining the study inputs under the appropriate conditions using appropriate methods and strategies will allow the study to be properly compatible with the real world. In addition to this study, the clarity level and several inputs should be considered in further studies.

Another point that should be emphasized is that, it should be taken into account that the use of traditional methods together with the social media analysis will produce substantial results. Using traditional methods can provide input to the system as well as verifying the accuracy of the output. Starting from this point of view, it is vital to use a traditional methods such as a survey study to demonstrate the accuracy of the study. To sum up, considering these factors in further studies will ensure the reliability of the study.

The biggest obstacle encountered in the research process is that, the comments of social media users who are not addicted to iPhone products limit the reliability of the research. There is no possible way to remove this restriction. Finally, another restriction is that, the events and mobilities in the world cause temporary changes in the brands' perception trend. Although these changes occur independently from the research, they cause the output to be obtained to deviate from the ideal value and limit the research at this point. 


\section{References}

Amron, A. (2018). The Influence of Brand Image, Design, Feature, and Price on Purchasing Decision of Apple IOS Smartphone in Surakarta, Indonesia. The International Journal of Social Sciences and Humanities Invention. 5 (12), 5187-5191. https://doi.org/10.18535/ijsshi/v5i12.15

Armstrong, G., Kotler, P., Opresnik, M. O. (2016). Marketing: An Introduction - Global Edition. Pearson Education.

Aswani, R., Kar, A.K., Ilavarasan, P.V., Dwivedi, Y.K. (2018). Search Engine Marketing Is Not All Gold: Insights from Twitter and SEOClerks. International Journal of Information $\begin{array}{llll}\text { Management. } & 38 & \text { (1), } & 107-116 .\end{array}$ https://doi.org/10.1016/J.IJINFOMGT.2017.07 .005

Bhardwaj, A., Narayan, Y., Pawan, V., Dutta, M. (2015). Sentiment Analysis for Indian Stock Market Prediction Using Sensex and Nifty. Procedia Computer Science. 70, 85-91. https://doi.org/10.1016/j.procs.2015.10.043

Charan, A. (2015a). Brand and Brand Image. Marketing Analytics, 3-22, https://doi.org/10.1142/ 9789814641371_0001

Charan, A. (2015b). Brand Equity. Marketing Analytics, 23-66, https://doi.org/10.1142/9789814641371_0002

Culotta, A., Cutler, J. (2016). Mining Brand Perceptions from Twitter Social Networks. Marketing $\begin{array}{llll}\text { Science. } & 35 & \text { (3), } & 343-362 .\end{array}$ https://doi.org/10.1287/mksc.2015.0968

Lee, T. Y., Bradlow, E.T. (2011). Automated Marketing Research Using Online Customer Reviews. Journal of Marketing Research. https://doi.org/10.1509/jmkr.48.5.881

Pournarakis, D. E., Sotiropoulos, D.N., Giaglis G.M. (2017). A Computational Model for Mining Consumer Perceptions in Social Media. Decision Support Systems. Vol.93, 98-110. https://doi.org/10.1016/ j.dss.2016.09.018

Vidya, N.A., Fanany, M.I., Budi, I. (2015). Twitter Sentiment to Analyze Net Brand Reputation of Mobile Phone Providers. Procedia Computer Science, $\quad 72, \quad 519-526$. https://doi.org/10.1016/j.procs.2015.12.159

\section{Appendix}

\section{Appendix I}

Table 6: Data Set Sample

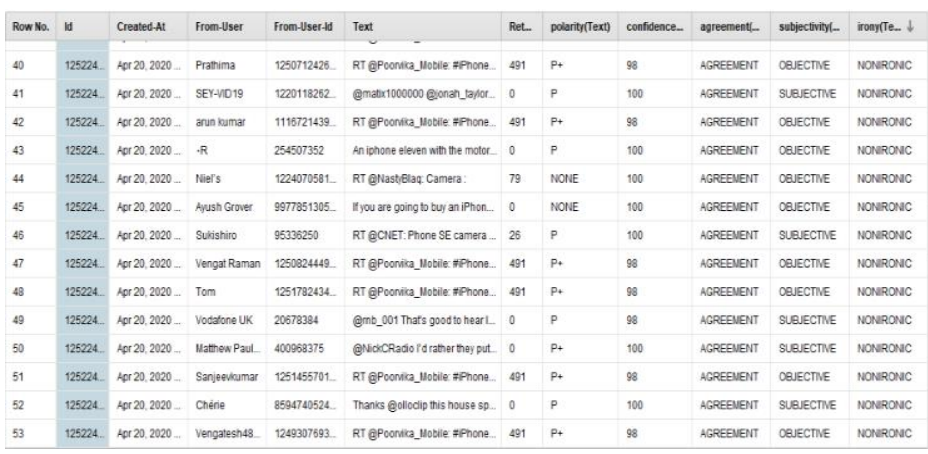

Questions asked to the participants during the focus group discussion are shown below:

1- Can you tell us a little bit about yourself?

2- If you purchase a phone, which brand would you prefer?

3- Have you ever used any a model of iPhone?

4- What do you think of iPhone?

5- What is your favorite feature of iPhone?

6- If the iPhone was a human, how would you describe it?

7- If you want to purchase an iPhone, what feature do you care about the most?

8- Why do you think other people prefer iPhone?

9- Would you like to add something? 